\title{
Revisiting the great earthqualke of Nepal 2015: Lessons learnt
}

\section{Lakhey S}

Shishir Lakhey, Professor, Department of Orthopaedics, Kathmandu Medical College, Kathmandu, Nepal

\begin{abstract}
T has been quite a while since the great 2015 earthquake. The question that was always asked before it happened was "Will it happen? Like the great earthquake of 1933 A.D.?" Some of us were in a state of denial, while others were hoping against hope that it would not come in their life time. It was not a question of 'if' it would come but rather 'when' it would come! It was just a matter of time before it would come, and it did come on Saturday noon of 21.04.2015.
\end{abstract}

Kathmandu Medical College (KMC) did have a disaster plan, but the disaster plan and drills were only to tackle 'External' disasters. A plan to tackle 'Internal' disaster was not yet in place. Certainly, a plan to tackle a 'Double Whammy combination of Internal and External' disaster was not yet in place! On 21.04.2015, after the quake, our hospital inpatients in Sinamangal, Kathmandu, spontaneously fled the buildings while the rest were evacuated to the hospital car park and Armed Police Force (APF) barracks in front of our hospital. This area subsequently functioned as a 'field' hospital in managing them. The situation in this 'field' hospital became even more challenging because earthquake victims seeking help also started pouring in. The patients stayed in the 'field' hospital for almost a week before the hospital shifted back to its original buildings.

Evacuation of patients from the hospital buildings during the earthquake was difficult. This was especially true for the Intensive Care Unit (ICU), Operation Theatre (OT), Post-operative ward, Orthopaedic patients on traction and other bedbound patients. Evacuation became much more difficult because lifts could not be used during those times and we did not have ramps in the hospital buildings. Evacuating patients from ICU, OT and postop wards on the sixth floor and the orthopaedic ward

Address for correspondence

Dr. Shishir Lakhey

Professor, Department of Orthopaedics

Kathmandu Medical College Teaching Hospital

Sinamangal, Kathmandu, Nepal

E-mail: slakhey64@yahoo.com on the fourth floor by carrying them down and across the road to establish a 'field' hospital in the car park and the APF barracks was difficult. To make the situation more difficult and chaotic, vehicles had to be first of all evacuated from the single entrance of the car park to accommodate patients being brought in. There were difficulties in establishing a 'field' hospital. The car park was dusty and uneven. APF barracks were even further away. Tents could not be bought, nor provided by the government. Patients had to be treated underneath 'paals' provided by local caterers. There was no access to government medical supplies as KMC was a nongovernment organization. Sanitation was difficult. We carried out operations in the room next to the generator room of APF, goods container, tents and later even in the nearby 'field hospital' of the Indian Army. Working conditions in general were understandably not good but we did what we could under those extraordinary circumstances.There were also challenges after moving back inside the hospital buildings. The challenge was in trying to normalize the work pattern of the hospital and providing early, definitive operative care to the trauma patients who were piling up. On the sixth day of the quake, we started operating seven theaters simultaneously in the sixth floor OT complex for 13 consecutive days. After the second big quake struck 19 days after the first big one, we were back in the car park and APF barracks. This time, healthcare providers and patients experienced a greater degree of psychological trauma. Recovering from it and shifting back to buildings became a more difficult and prolonged affair. Some departments took as long as 10 days to shift back inside. Such was the amount of fear created by the earthquake. Operating on the sixth floor OT was not possible for a long time after second big quake but we started operating again, after seven days of the second big earthquake, in the first floor of the Neurosurgery OT.

Hospital statistics showed that we treated 1292 disaster victims in the emergency. We admitted 595 victims and operated a total of 234 cases ( 150 major, 74 intermediate and 10 minor). There are several important lessons to be 
learned from this experience. Other teaching hospitals in Kathmandu like Tribhuvan University Teaching Hospital (TUTH) and Dhulikhel hospitals with three or four stories of documented earthquake resistant structures and having OTs in the first floor started operating on the day or the second day of the earthquake. The patients of those hospitals who had fled the buildings also returned back to the buildings much earlier. Therefore, hospital buildings should preferably be three or four storied with certified earthquake resistant structures which can tremendously increase the confidence of the patients and caretakers alike. Hospitals should have patient evacuation/transportation ramps and a lot of open space in its premises. The OTs, ICUs and other high dependency units should preferably be in the first or second floors. An open space needs to be identified inside or in close proximity to the hospital premises which can be organized to act as a field hospital in case of an 'internal' disaster when the hospital has to be evacuated. A field hospital plan needs to be formulated with definitive areas allocated for different functioning areas. Provisions need to be made for storage of tents, makeshift OTs, portable x-rays, generators and other disaster stocks in a goods container which will keep it safe and make it easily accessible during the time of need. All departments in the hospital need to conduct regular Table Top Drills to familiarize everyone with their respective roles in disaster management. Complete disaster drills should be conducted periodically and be familiar to everyone working in the hospital.

Hospitals play a crucial role in the socioeconomic and psychological recovery of the population after a disaster. Hospitals are considered important due to their roles in saving lives in the affected population and must be able to withstand hazards and remain functioning during and after a disaster ${ }^{1}$. There are guidelines for assisting health-sector professionals and authorities to implement qualitative assessments of structural and non-structural earthquake vulnerability of hospitals and health institutions ${ }^{2}$. It would be important for hospital engineers and managers to go through the guidelines and implement them. The "four pillars of hospital preparedness" including structural, nonstructural, functional and human resources need to be strengthened ${ }^{1,3}$. Taking heed of the lessons learnt from living through and managing the 'disaster' situation of the great earthquake and being more prepared for any such eventuality in future would be the logical thing to do. Who knows when the next one will strike again?

\section{REFERENCES}

1. Mulyasari F, Inoue S, Prashar S, Isayama K, Basu M, Srivastava N, Shaw R. Disaster Preparedness: Looking through the Lens of Hospitals in Japan.Int. J. Disaster Risk Sci. 2013, 4 (2): 89-100.

2. Guidelines for Seismic Vulnerability Assessment of Hospitals prepared by National Society for Earthquake Technology-Nepal (NSET) and World Health Organization (WHO).

3. Safe Hospitals in Emergencies and Disasters: Structural, Non-structural and Functional Indicators. (Project of the World Health Organization (WHO) Regional Office for the Western Pacific with support from the European Commission Humanitarian Aid department (ECHO) as part of the regional implementation of the global Campaign on Hospitals Safe from Disasters.) 